\title{
Analysis on the Common Problems of Metering Gateway Table Zhitong Liu ${ }^{1}$, Yi Wang ${ }^{1}$, Yanjun Pang ${ }^{2}$, Lei Wang ${ }^{2}$, Lishuai $\mathrm{He}^{3}$, Xue Wang ${ }^{2}$, Xin Liu' ${ }^{2}$, Hui Miao ${ }^{2}$, Xiaoshu Zhang ${ }^{2}$, Hui Tang ${ }^{2}$ \\ ${ }^{1}$ Metering Center, State Grid Liaoning Electric Power Co., Ltd. \\ ${ }^{2}$ Fushun power supply company, State Grid Liaoning Electric Power Co., Ltd. \\ ${ }^{3}$ Maintenance branch company, State Grid Liaoning Electric Power Co., Ltd.
}

Keywords: metering gateway table; electric energy metering device; electric energy metering system

\begin{abstract}
The metering gateway table plays an important role in the electric energy measurement of power grid.The abnormal situation in the field operation will affect the accuracy and reliability of the gateway energy metering.The problems occurred in the operation are mainly related to the particularity of the gateway energy metering, the complexity of the meter function and the operation maintenance.In order to solve and avoid these problems, strictly abide by the requirements of the relevant procedures for the field inspection work instruction of the electric energy metering device.Strengthen the operation management and maintenance of metering gateway table.At the same time, the function of the electric energy metering system is improved to ensure the normal operation of metering gateway table.
\end{abstract}

\section{Introduction}

Gateway table definition.For example, 1 transformer power supply area has $\mathrm{N}$ households. Each household has 1 metering meters for recording the use of electricity. In the transformer is equipped with 1 metering meters, used to record the total power of the entire transformer. The meter which is installed in the transformer position is called the metering gateway table.In the substation, each line also has 1 electric energy meter, which is used to record the power of the whole line (1 lines carrying $\mathrm{N}$ transformers). Relative to the transformer meter, it is also the metering gateway table. The main function of the metering gateway table is to record the total output power, and calculate the loss by using the recorded electric quantity and the electric quantity of the user table.

The relevant information of the metering gateway table can be used as a reference for the settlement of trade and the assessment of internal economic indicators.0.2S level multi-function meter is widely used.The metering gateway table plays an important role in the electric energy measurement of power grid.These problems are related to the particularity of metering gateway table, the complexity of function and , maintenance management.The following will be the main problems in the operation of the metering gateway table in the analysis and put forward specific solutions.

\section{Internal Wiring Structure of Metering Gateway Table}

The internal wiring structure of the metering gateway table is shown in figure 1. Taking A phase voltage and current as an example. 


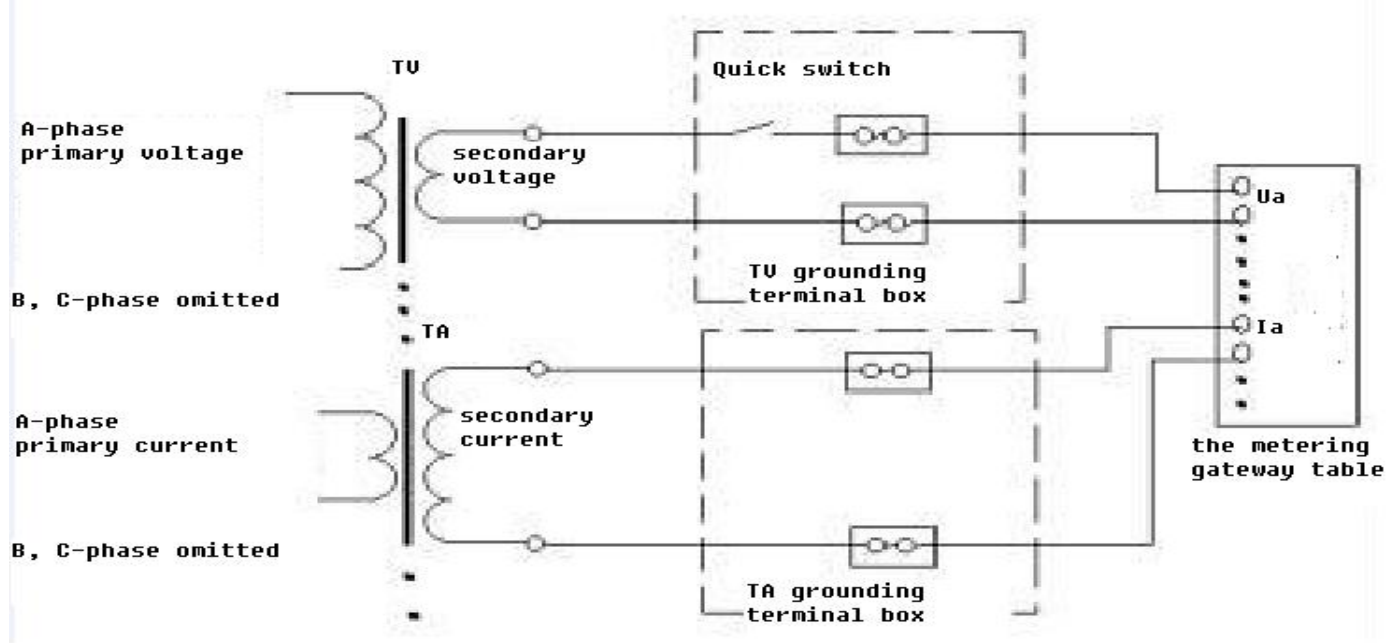

Fig. 1 wiring diagram of metering gateway table

Notes: TV-Voltage transformer; TA-Current transformer

\section{Field Load Test of Metering Gateway Table}

Field load test is an important item in the operation and management of the metering gateway table.In the part position of the power grid, the speed of the change of the power flow is fast, the load is low, and the function of the metering gateway table is more complicated, which brings some difficulties to the field error test and the function check.In the field of electric energy metering device inspection work instructions, the detailed requirements of the safety requirements, inspection items, inspection conditions, inspection methods, etc..This regulation has important guiding effect on the spot inspection[1].

Special attention should be paid to the following points on site inspection:

(1) Strict implementation of DL 409 - 1991 "electrical safety regulations".Voltage transformer secondary circuit should not be shorted. Current transformer secondary circuit should not be disconnected.Current terminals must be monitored when they are switched on and off.Joints are not allowed in the middle of the wire. The current connection terminal of the standard meter should have the function of self-locking.

(2) Prior to the field inspection, the test conditions should be determined first.The following 3 cases should not be carried out error measurement: load current is lower than the rated current of $10 \%$ (for the $\mathrm{S}$ level of the electric energy meter is $5 \%$ ), the power factor is less than 0.5 , the load change.

(3) Check the wiring of the meter. Check the terminal position of the electric energy meter. This work should be carried out as soon as possible.

(4) Check whether the main function is normal. Use GPS time or Beijing time as standard clock. Using special software to read and save the relevant data of the metering gateway table, such as the bottom value, the clock state, the battery state, voltage loss records, event records, load curves and other data. Then check its correctness. Clock calibration should be carried out when the clock error is larger. Battery failure should be promptly replaced batteries.

\section{The Metering Gateway Table Original Electric Energy Information Data Recording Function}

The data of the original electric energy information include: the bottom value, the freezing value and the load curve value.In the field of electric energy metering system, which type of data is used as the basis for settlement is a controversial issue.The bottom value refers to the accumulated energy value recorded from the date of installation to the current time.At the beginning of installation, the bottom value is generally zero, the unit is $\mathrm{kWh}$ or Wh. The freezing value refers to the value of the bottom value, at the end of a settlement period.The freezing value will be stored in 
the register.The freezing value is no longer changed after being saved, unit kWh or Wh.The load curve value refers to the cumulative number of electric energy pulses recorded in a given time interval,the unit is $\mathrm{imp} / \mathrm{kWh}$ or $\mathrm{imp} / \mathrm{Wh}$. In the verification regulation of "electronic watt hour meter", there are corresponding technical requirements and verification methods for the accuracy of the bottom value.The freezing value is a special value of the bottom value that is copied and saved at a specific time.The freezing value does not affect the accuracy of the electric energy measurement. There is no specific requirement for load curve value in the verification regulation .Therefore, only the bottom value and freezing value meet the traceability and legitimacy.

Settlement time is usually at zero moment.Because of the delay of data acquisition communication, it is impossible to collect all the bottom values at the same time.Because the value of the bottom value is constantly changing, there is a certain error between the electric energy metering system measured value and the actual value.However, the freezing value and the load curve value can be recorded immediately, and will not be accumulated.Therefore, in the process of collection, there is no error in the freezing value, load curve value and actual value collected by the electric energy metering system. The acquisition of freezing value and load curve value is not affected by data acquisition communication delay.Compared with the standard clock, there are some errors in the clock of the metering gateway table, so the freezing value and the load curve value may also have errors. If the clock of the metering gateway table can be checked and calibrated regularly, the error caused by the clock will be reduced.

To sum up,the bottom value and freezing value meet the traceability and legitimacy.As the basis of settlement, the bottom value is affected by the data acquisition communication delay, and the freezing value and the load curve value are affected by the clock accuracy.If the clock of the metering gateway table can be checked and calibrated regularly, the error caused by the clock will be reduced.In addition, the freezing value and load curve value can be stored for a long time. The freezing value and the load curve data are not easy to lose.Therefore, under the premise of ensuring the accuracy of the metering gateway table clock, the choice of frozen value as the basis for settlement is more practical.

\section{On Line Monitoring of the Metering Gateway Table Running State}

The metering gateway table failure in operation may be various, such as hardware failures, phase error, clock failure, battery failure etc..Most of the faults are more subtle, and it is not easy to be found during inspection.Faults exist for a long time, and the accuracy of metering gateway table is seriously affected.These hidden faults will be detected only after the occurrence of a large electrical energy metering error or on a periodic inspection of the metering gateway table.Therefore, by monitoring the running state of the metering gateway table, the fault is discovered early and treated as soon as possible.Now most of the metering gateway table has access to the electric energy metering system, through the improvement of the system function to achieve the online monitoring and fault alarm. The main function of the system should be:

(1)In addition to collecting various data information of electric energy, should also collect metering gateway table state information (such as phase error, clock, battery status, access to records and other events).

(2)The system should check the validity of the collected data, including: integrated error check 、 principal and subordinate table check v generatrix energy balance check etc.

(3)When the fault or abnormal event occurs, the system should remind the alarm information, so that the relevant personnel to the scene as soon as possible.

\section{Correction Method of Gateway Metering Power}

The electric energy measurement is directly related to the economic benefits of the enterprise. When the electric energy metering device fails, it is necessary to use a certain method to modify the electric quantity. At present, the compensation and correction measures of the gateway energy are mainly: 


\section{Principal and Subordinate Table Method}

The principal and subordinate table method refers to the same position in the installation of 2 with the level of the metering gateway table.Two tables use the same set of voltage transformer, current transformer and two secondary circuit.One table as the principal table for settlement.Another table as a subordinate table for reference.Once the master table is determined, it can not be exchanged freely. The principal and subordinate table should be checked regularly, if the difference between the two values exceeded the allowable range should be looking for specific reasons.If only one table is wrong, the other table is used for settlement.If there is an error in each of the two tables, other methods should be used to correct the electrical energy.This method is applicable to only one table error. This method does not apply to the case of two tables are wrong.This method does not apply to the voltage transformer, current transformer, the secondary circuit caused by the error.

\section{Generatrix Energy Balance Method}

In this way, the metering gateway table needs to be installed on all incoming and outgoing positions of the generatrix. When one metering gateway table error occurs, in accordance with the principle of generatrix energy balance, by means of the other bus metering gateway table power and line loss power, further calculates the numerical error of the fault table.The generatrix energy balance method is suitable for the situation , the metering gateway table is installed on all incoming and outgoing positions of the generatrix.

\section{Double Table Method}

Double table method [2] refers to both ends of the line is equipped with electric energy metering device.One set of electric energy metering device is used for settlement. The other set as a spare metering device.Regularly check the same period of time the line of two sets of electricity values.Once beyond the allowable range of line loss should be immediately to the scene to find the cause.According to the data provided by the normal electric energy metering device, and considering the power loss of the line, the electric quantity correction. The method is applicable to a wide range, but it is necessary to accurately calculate the line loss in the time of equipment failure.

\section{Duty Log Method}

The duty log method is the method of calculating the corrected electric quantity by using the error time span of the gateway meter multiplied by the average load of the line. The load of the gateway line in the run record is used as the average load.If the exact time of the error can not be known, you can choose the most close to the wrong time of the two meter reading time as a basis for the calculation of the time span.Duty log method do not need to calculate the line loss of electricity, relatively simple and practical.

When the voltage transformer, current transformer and the the secondary circuit of the electric energy metering device have no errors, the method of principal and subordinate table is preferred. When the voltage transformer, current transformer and the the secondary circuit of the electric energy metering device are in error, the method of double table is preferred. At least two methods should be selected when the electricity quantity is corrected. The two methods can be used to verify each other. At the same time, it can also be used to verify the accuracy of the corrected electric quantity by referring to the relevant data of the load curve, the voltage loss record, the substation operation record and the electric energy billing system.

\section{Low Load Operation of Metering Gateway Table}

Due to the influence of the operation mode, the load fluctuation of the contact line of the power grid is large, and it is often in the state of low load current and low power factor.Some load current is less than $5 \%$ of current transformer rated primary current.Usually in the selection of meter rated current value, reference to the current transformer rated secondary current to determine, so leading to the metering gateway table in the low load operation.Therefore, according to the DL/T448 - 2000 "electric energy metering device technical management regulations" requirements to select the type of gateway table.The rated current of the metering gateway table shall not 
exceed $30 \%$ of the current transformer rated secondary current.The maximum allowable current of the the metering gateway table should be about $120 \%$ of the current transformer rated secondary current[3].

\section{Conclusion}

At present, most of the gateway meter adopts imported high-grade multi-function electric energy meter. The problems occurred in the operation are mainly related to the particularity of the gateway energy metering, the complexity of the meter function and the operation maintenance. Therefore, in strict accordance with the "electric energy metering device on-site inspection work instructions" and other relevant regulations, strengthen the maintenance and management work. At the same time, optimize the function of the gateway table and the electric energy metering system to ensure the normal operation of the metering gateway table.

\section{References}

[1] State grid production and operation department. Electric energy metering device on-site inspection work instruction

[2] Zhihong Pan. Correction method of gateway metering power[J].China power press, 2003

[3] People's Republic of China State Economic and Trade Commission.DL/T448-2000 electric energy metering device management regulations, China Electric Power Press, 2001

[4] Xiaoxi Yang. Analysis of the main problems of the domestic power grid gateway table operation [J]. global meter Chinese edition, 2005 